Pacific Journal of Mathematics

TWO BRIDGE KNOTS ARE ALTERNATING KNOTS 


\title{
TWO BRIDGE KNOTS ARE ALTERNATING KNOTS
}

\author{
R. E. GOODRICK
}

\begin{abstract}
H. Schubert introduced a numerical knot invariant called the bridge number of a knot. In particular, he classified the two-bridge knots and proved that they were prime knots. Later, Murasugi showed that if $K$ is an alternating knot then the matrix of $K$ is alternating. The latter is true of twobridge knots. The purpose of the following is to give a somewhat unusual geometric presentation of two-bridge knots from which it will be seen that they are alternating knots.
\end{abstract}

By a knot we will mean a polygonal simple closed curve in $E^{3}$. Let $C$ denote the unit circle in the $x y$ plane and $f$ a homeomorphism from $C$ to a knot $K$. We will assume that $K$ is in a regular position with respect to a projection into the $y=0$ plane [1] and that those points of $K$ which do not have unique images will be the crossing points of $K$. Let $f^{-1}\left(a_{1}\right), f^{-1}\left(a_{2}\right), \cdots, f^{-1}\left(a_{2 n}\right)$ be the points of $C$ ordered clockwise where $a_{1}$ are the crossing points of $K$. If $K$ has a presentation with an associated $f$ such that $a_{i}$ is an overcrossing point if and only if $i$ is odd, then $K$ is said to be an alternating knot. By a twobridge knot we mean a nontrivial knot in $E^{3}$ which can be represented by two linear segments through a convex cell and two arcs on the boundary of the cell.

TheOREM 1. If $K$ is a two-bridge knot, then $K$ is an alternating knot.

Proof. We will start with $K$ in a two-bridge representation (Fig. 1a) and apply several space homeomorphisms to $E^{3}$, so that the resulting representation of $K$ is described by an arc 'monotonely' approaching the center of the cube and four linear segments (Fig. 1b). The proof

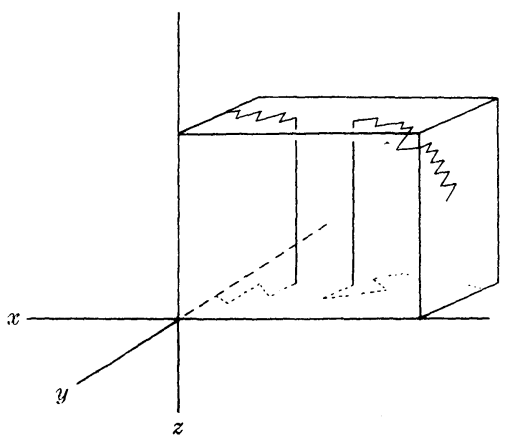

Figure 1a.

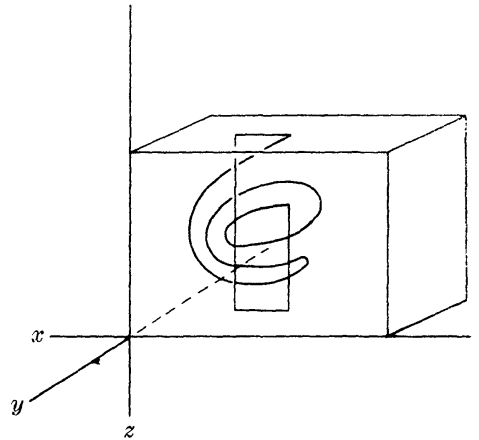

Figure $1 b$ 
will be completed by proving a lemma that shows that this representation is an alternating representation.

First assume that the knot $K$ is respresented by two ares $A_{i}=$ $\{(x, y, z) \mid x=i / 3, y=1 / 2,0 \leqq z \leqq 1\}, i=1,2$, through the cube $I=$ $\{(x, y, z) \mid 0 \leqq x \leqq 1,0 \leqq y \leqq 1,0 \leqq z \leqq 1\}$ and two connecting arcs on the boundary of $I$, i.e. $B_{1}$ and $B_{2}$. Furthermore, we can assume that $B_{1} \cup B_{2}$ does not intersect the planes $y=0$ and $y=1$ (Fig. 2).

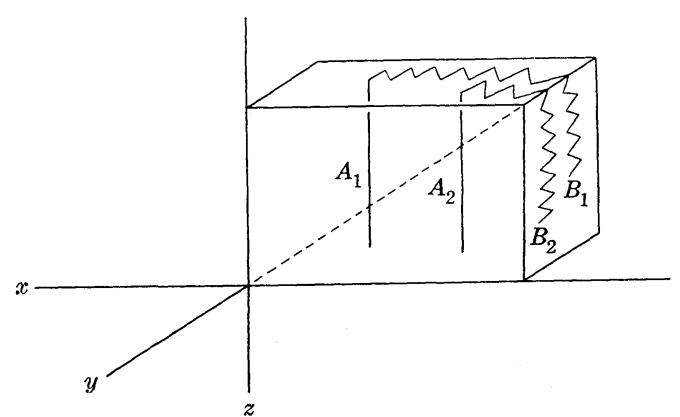

Figure 2.

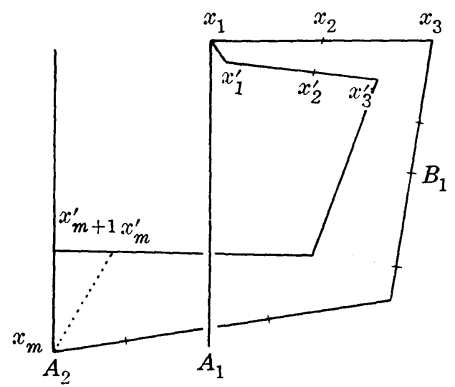

Figure 3.

The first homeomorphism $h_{1}$ will move the arc $B_{1}$ to an arc starting at the boundary and monotonely approaching the center of $I$ so that it will not cross itself (in the $y$ direction). $h_{1}$ will be constructed by the following five steps:

(1) Move $B_{1}$ on the boundary of $I$, leaving the $A_{i}$ fixed, so that no segment of $B_{1}$ lies on the simple closed curve defined by (boundary of $I) \cap$ (the plane $y=1 / 2$ ).

(2) Define $L$ to be the cone from the center of $I$ to $B_{1}$ and define $O_{t}$ to be the annulus $\{(x, y, z) \mid \max (x-1 / 2, z-1 / 2)=1 / 2-t, 0 \leqq y \leqq$ $1\}, 0 \leqq t \leqq 1 / 2$.

(3) From (1) we have $L \cap\left(A_{1} \cup A_{2}\right)$ equal to a finite set of points. Hence define $\varepsilon$ so that the interior of $\bigcup_{0}^{\varepsilon} O_{t} \cap L$ contains no point of $A_{1} \cup A_{2}$.

(4) Let $x_{1}, \cdots, x_{m}$ be the vertices of $B_{1}$ ordered from $A_{1}$ to $A_{2}$. If $1 \leqq k \leqq m$, let $x_{k}^{\prime}$ be the point common to $O_{k \varepsilon / m+1}$ and the linear segment joining $x_{k}$ to the center of $I$ and let $x_{m+1}^{\prime}=O_{\varepsilon} \cap A_{2}$.

(5) $L \cap \bigcup_{0}^{\varepsilon} O_{t}$ is a disk whose intersection with $K$ is $B_{1}$. Hence the vertices $x_{1}^{\prime}, x_{2}^{\prime}, \cdots, x_{m}^{\prime}, x_{m}^{\prime}, \cdots, x_{1}$ determine a simple closed curve which bounds a disk in $\bigcup_{0}^{\varepsilon} O_{t}$ whose intersection with $K$ is $B_{1}$. Move $B_{1}$ to $x_{1}, x_{1}^{\prime}, \cdots, x_{m}^{\prime}, x_{m}$ without moving $A_{1} \cup A_{2} \cup B_{2}$. Then move $x_{m+1}^{\prime} x_{m} x_{m}^{\prime}$ to the segment $x_{m+1}^{\prime} x_{m}^{\prime}$ without moving the rest of $K$ (Fig. 3).

The points of $h_{1}\left(B_{1}\right)$ approach the center of $I$ in the sense that if $x_{i}^{\prime}, x_{j}^{\prime}$ are vertices of $h_{1}\left(B_{1}\right)$ such that $i<j$ and $x_{i}^{\prime} \varepsilon O_{t_{i}}, x_{j}^{\prime} \varepsilon O_{t_{j}}$, then $t_{i}<t_{j}$. Hence if $h_{1}(K)$ is projected in the $y$ direction, $h_{1}\left(B_{1}\right)$ will not cross itself. 
As $h_{1}(K) \cap$ (boundary of $\left.I\right)=B_{2} \cup\left|x_{1}\right|$, we can find a homeomorphism $h_{2}$ such that $h_{2}$ is fixed on $A_{1} \cup\left\{A_{2}-\left|x_{m+1}^{\prime}, x_{m}\right|\right\} \cup h_{1}\left(B_{1}\right)$ and $h_{2}$ takes $B_{2}$ to an arc on the simple closed curve formed by (boundary of $I) \cap$ (plane $y=1 / 2$ ).

Next, we will define a homeomorphism $h_{3}$ which will move $h_{1}\left(B_{1}\right)$ so that the crossings of $h_{3}\left(h_{1}\left(B_{1}\right)\right)$ will alternate with respect to a projection in the $y=0$ plane and $h_{3}\left(h_{1}\left(B_{1}\right)\right)$ will still approach the center of $I$ monotonely. Let $\mathrm{b}_{1}, b_{2}, \cdots, b_{r}$, be the crossing points of $h_{1}\left(B_{1}\right)$ ordered from $A_{1}$ and let $E_{1}=A_{1} \cap\{(x, y, z) \mid z \geqq 1 / 2\}, E_{2}=A_{1} \cap$ $\{(x, y, z) \mid z \leqq 1 / 2\}$, and $E_{3}=A_{2}-\left[x_{m}, x_{m+1}\right]$. A two valued function $g$ may be defined on $\left\{b_{i}\right\}$ so that $g\left(b_{i}\right)=0$ if $b_{i}$ is an over-crossing and $g\left(b_{i}\right)=u$ if $b_{i}$ is an undercrossing (in the $y$-direction). Assume that two successive values of $g$ are equal and then there are essentially two cases; i.e., case $a, b_{i}$ and $b_{i+1}$ both lie above (or below) $E_{1}, E_{2}$, or $E_{3}$, and case $b, b_{i}$ lies above (or below) $E_{l}$ and $b_{i+1}$ lies above (or below) $E_{k}$ with $l \neq k$.

If case a holds, then there exists $t^{\prime}$ and $t^{\prime \prime}$ such that $\mathbf{U}_{t^{\prime} \leqq t \leqq t^{\prime \prime}} O_{t}$ contains only $b_{i}$ and $b_{i+1}$ as crossings of $h_{2} h_{1}(K)$. There is an arc $\alpha$, such that (1) $\alpha \subset \bigcup_{t^{\prime} \leqq t \leqq t^{\prime \prime}} O_{t}$ (2) $\alpha$ has endpoints $h_{1}\left(B_{1}\right) \cap O_{t^{\prime}}$ and $\left.h_{1}\left(B_{1}\right) \cap O_{t^{\prime}}, 3\right) \alpha$ does not cross $E_{1}, E_{2}$ or $E_{3}$ and (4) $\alpha$ monotonely approaches the center of $I$. Let $f_{i}$ be a space homeomorphism moving $h_{1}\left(B_{1}\right) \cap \bigcup_{t^{\prime} \leqq t \leqq t^{\prime \prime}} O_{t}$ to $\alpha$ and leaving $E_{1} \cup E_{2} \cup E_{3}$ and $E^{3}-\left[\bigcup_{t \leqq t \leqq t^{\prime \prime}} O_{t}\right]$ fixed (Fig. 4).

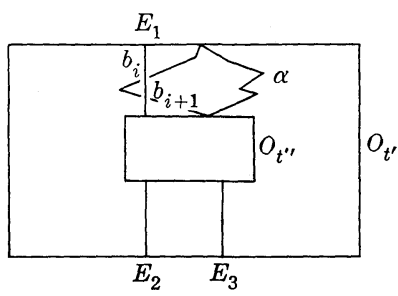

Figure 4.

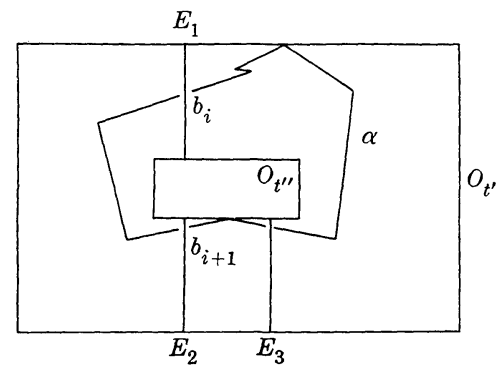

Figure 5.

If case $b$ holds, define $t^{\prime}, t^{\prime \prime}$, and $\alpha$ as above, except $\alpha$ will cross the third $E$ segment once in the same way that $h_{1}\left(B_{1}\right)$ crosses the other two. Define $f_{1}$ as a space homeomorphism taking $h_{1}\left(B_{1}\right) \cap$ $\bigcup_{t^{\prime} \leqq t \leqq t^{\prime \prime}} O_{t}$ to $\alpha$ and leaving $E_{1} \cup E_{2} \cup E_{3}$ and $E^{3}-\left[\bigcup_{t^{\prime} \leqq t \leqq t^{\prime \prime}} O_{t}\right]$ fixed (Fig. 4).

Hence if $h_{2} h_{1}\left(B_{1}\right)$ is not alternating then there exists a sequence of $\left\{f_{i}\right\}$ such that $f_{i_{1}} f_{i_{2}} \cdots f_{i_{k}} h_{2} h_{1}\left(B_{1}\right)$ is alternating. Let $h_{3}=f_{i_{1}} f_{i_{2}} \cdots f_{i_{k}}$. Then $h_{3} h_{2} h_{1}(K)$ is alternating by the following lemma.

LeMma 1. Let $K$ be a knot in regular position with respect to 
the $y=0$ plane, and $B$ a subarc of $K$ such that (1) $B$ does not cross itself, (2) every crossing of $K$ has exactly one crossing point in $B$, and (3) the crossings of $B$ alternate, then $K$ is an alternating knot.

Proof. It can be assumed that $B=\{(x, y, z) \mid 0 \leqq x \leqq 1, y=0$, $z=0\}$ and $B$ satisfies conditions (1) through (3). If $K$ is not an alternating knot, then there are two successive crossings of $K, b_{1}, b_{2}$, such that both $b_{1}$ and $b_{2}$ are overcrossings (or undercrossings). Let $A$ be the arc joining $b_{1}$ and $b_{2}$ which has no crossings in its interior (Fig. 6). As the crossings of $B$ alternate, $A$ cannot lie in $B$.

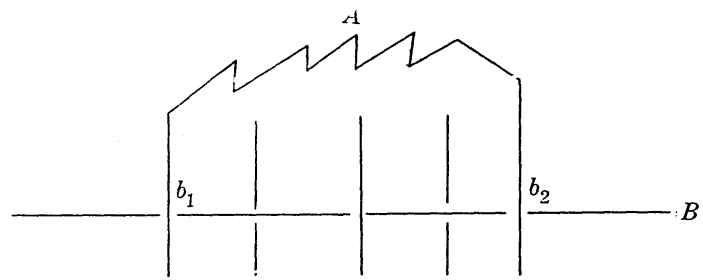

Figure 6 .

$A$ cannot contain both endpoints of $B$. If $A$ contains neither endpoint of $B$, define $C$ to be the simple closed curve containing $A$, the subarc $B^{\prime}$ of $B$ with endpoints below (above) $b_{1}$ and $b_{2}$, and the two vertical segments joining $b_{1}$ and $b_{2}$ to their respective undercrossing (overcrossing) points. If $K$ contains a single endpoint of $B$, define $C$ to be the simple closed curve containing $A$, the subarc $B^{\prime}$ of $B$ containing one of $b_{1}$ or $b_{2}$ in its interior and having as endpoints the other $b_{i}$ and the endpoint of $B$ in $A$, and the vertical segment joining the $b_{i}$ endpoint of $B^{\prime}$ to $A$.

As the crossings of $B$ alternate and $b_{1}$ and $b_{2}$ are both overcrossing points, there is an odd number of crossings on $B^{\prime}$ between $b_{1}$ and $b_{2}$, and hence an odd number of crossings on $C . C \cup K$ is the union of three simple closed curves, $C, C_{1}$, and $C_{2}\left(C_{2}\right.$ is possibly degenerate). But $C_{1} \cup C_{2}$ must cross $C$ an even number of times, contradicting the fact that $C$ is crossed an odd number of times.

\section{REFERENCES}

1. R. Crowell and R. Fox, Introduction to Knot Theory, Ginn C., 1963.

2. K. Murasugi, On the Alexander polynomial of the alternating knot, Osaka Math.

J., 10 (1958), 181-189.

3. H. Schubert, Uber Eine Numerishe Knot. an invariante, Math. Z., 61 (1954), 254-288.

4. - Knoten Mit Zwei Brucken, Math. Z., 65 (1956), 133-170.

Received August 24, 1970.

California State College, Hayward 


\section{PACIFIC JOURNAL OF MATHEMATICS}

\section{EDITORS}

\section{H. SAMELSON}

Stanford University

Stanford, California 94305

\section{R. HOBBY}

University of Washington Seattle, Washington 98105

\section{J. DugundJI}

Department of Mathematics University of Southern California Los Angeles, California 90007

RICHARD ARENS

University of California Los Angeles, California 90024

\section{ASSOCIATE EDITORS}
E. F. BECKENBACH
B. H. Neumann
F. WoLF
K. YoSHIDA

\section{SUPPORTING INSTITUTIONS}

UNIVERSITY OF BRITISH COLUMBIA CALIFORNIA INSTITUTE OF TECHNOLOGY

UNIVERSITY OF CALIFORNIA

MONTANA STATE UNIVERSITY

UNIVERSITY OF NEVADA

NEW MEXICO STATE UNIVERSITY

OREGON STATE UNIVERSITY

UNIVERSITY OF OREGON

OSAKA UNIVERSITY

\author{
UNIVERSITY OF SOUTHERN CALIFORNIA \\ STANFORD UNIVERSITY \\ UNIVERSITY OF TOKYO \\ UNIVERSITY OF UTAH \\ WASHINGTON STATE UNIVERSITY \\ UNIVERSITY OF WASHINGTON \\ * * * * \\ AMERICAN MATHEMATICAL SOCIETY \\ NAVAL WEAPONS CENTER
}

The Supporting Institutions listed above contribute to the cost of publication of this Journal, but they are not owners or publishers and have no responsibility for its content or policies.

Mathematical papers intended for publication in the Pacific Journal of Mathematics should be in typed form or offset-reproduced, (not dittoed), double spaced with large margins. Underline Greek letters in red, German in green, and script in blue. The first paragraph or two must be capable of being used separately as a synopsis of the entire paper. The editorial "we" must not be used in the synopsis, and items of the bibliography should not be cited there unless absolutely necessary, in which case they must be identified by author and Journal, rather than by item number. Manuscripts, in duplicate if possible, may be sent to any one of the four editors. Please classify according to the scheme of Math. Rev. Index. to Vol. 39. All other communications to the editors should be addressed to the managing editor, Richard Arens, University of California, Los Angeles, California, 90024.

50 reprints are provided free for each article; additional copies may be obtained at cost in multiples of 50 .

The Pacific Journal of Mathematics is published monthly. Effective with Volume 16 the price per volume (3 numbers) is $\$ 8.00$; single issues, $\$ 3.00$. Special price for current issues to individual faculty members of supporting institutions and to individual members of the American Mathematical Society: $\$ 4.00$ per volume; single issues $\$ 1.50$. Back numbers are available.

Subscriptions, orders for back numbers, and changes of address should be sent to Pacific Journal of Mathematics, 103 Highland Boulevard, Berkeley, California, 94708.

PUBLISHED BY PACIFIC JOURNAL OF MATHEMATICS, A NON-PROFIT CORPORATION

Printed at Kokusai Bunken Insatsusha (International Academic Printing Co., Ltd.), 270, 3-chome Totsuka-cho, Shinjuku-ku, Tokyo 160, Japan. 


\section{Pacific Journal of Mathematics}

\section{Vol. 40, No. $3 \quad$ November, 1972}

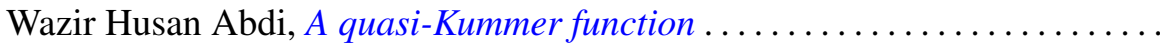

Vasily Cateforis, Minimal injective cogenerators for the class of modules of

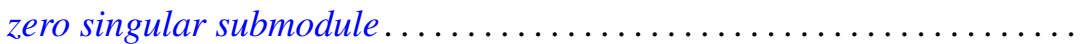

W. Wistar (William) Comfort and Anthony Wood Hager, Cardinality of

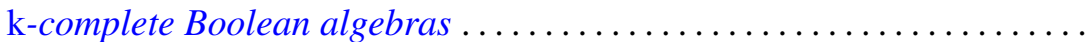

Richard Brian Darst and Gene Allen DeBoth, Norm convergence of martingales of Radon-Nikodym derivatives given a $\sigma$-lattice ..........

M. Edelstein and Anthony Charles Thompson, Some results on nearest points and support properties of convex sets in $c_{0} \ldots \ldots \ldots \ldots \ldots$

Richard Goodrick, Two bridge knots are alternating knots .

Jean-Pierre Gossez and Enrique José Lami Dozo, Some geometric properties related to the fixed point theory for nonexpansive mappings ..........

Dang Xuan Hong, Covering relations among lattice varieties .............

Carl Groos Jockusch, Jr. and Robert Irving Soare, Degrees of members of $\Pi_{1}^{0}$

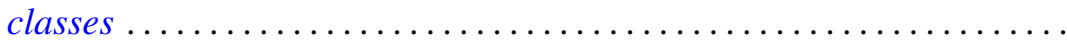

565

575

605

Leroy Milton Kelly and R. Rottenberg, Simple points in pseudoline

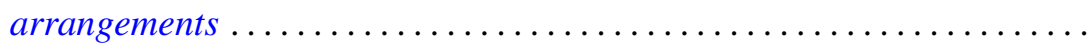

Joe Eckley Kirk, Jr., The uniformizing function for a class of Riemann surfaces....

Glenn Richard Luecke, Operators satisfying condition $\left(G_{1}\right)$ locally ... 629

T. S. Motzkin, On L $(S)$-tuples and l-pairs of matrices ... . .

Charles Estep Murley, The classification of certain classes of torsion free

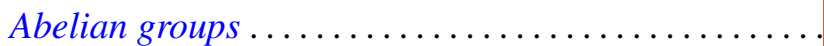

Louis D. Nel, Lattices of lower semi-continuous functions and associated topological spaces.

David Emroy Penney, II, Establishing isomorphism between tame prime

knots in $E^{3}$. . .

Daniel Rider, Functions which operate on $\mathscr{F} L_{p}(T), 1<p<2$

Thomas Stephen Shores, Injective modules over duo rings ...

Stephen Simons, A convergence theorem with boundary. .

703

Stephen Simons, Maximinimax, minimax, and antiminimax theorems and a

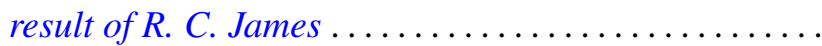

Stephen Simons, On Ptak's combinatorial lemma ........

Stuart A. Steinberg, Finitely-valued $f$-modules............

Pui-kei Wong, Integral inequalities of Wirtinger-type and fourth-order

elliptic differential inequalities .

Yen-Yi Wu, Completions of Boolean algebras with partially additive

operators ..................................

Phillip Lee Zenor, On spaces with regular $G_{\delta}$-diagonals . . . 